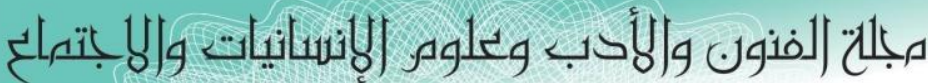

Journal of Arts, Literature, Humanities and Social Sciences

ISSN online: 2414 - 3383

ISSN print: 2616 - 3810

أيلول -سبتمبر 2019

(43) (4) (العدد)

\title{
كتمان الأسرار في نظام الخلافة الإسـلامية
}

\author{
جلال سليمان عبدالله عزيز
}

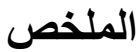

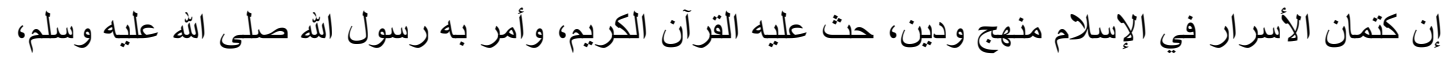

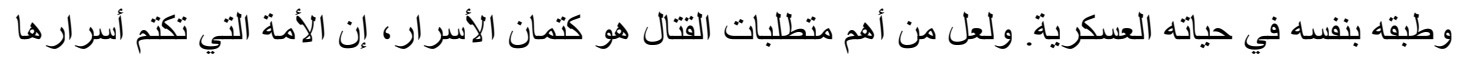

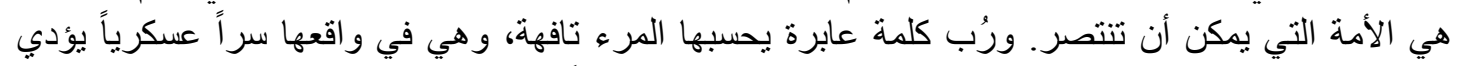

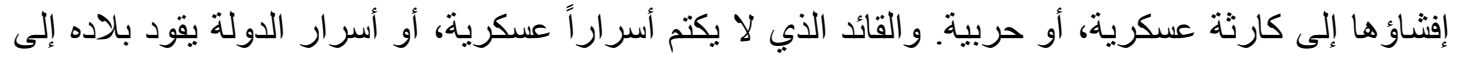

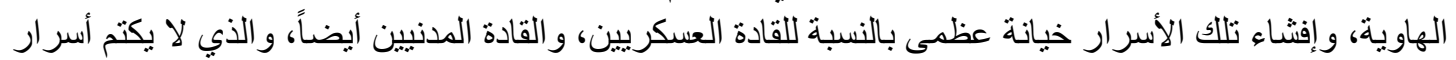
أمته، فإن وجوده بين أفر اد الأمة كوجود عدو من الأعداء.
\end{abstract}

\section{Concealment of Secrets in The System of Islamic Caliphate}

\begin{abstract}
Keeping secrets is method and religion in islam, holy qur'an call on it and also the prophet orders with it and applies it in his militry life.

Keeping secrets is very needed in the war, and the nation who can keep its secrets can victory.Sometimes there is a word someone thinks it is useless, but actually it is military secres led to military disaster if it comes up.

Leader who can't keep his country or militry secrets may leds his country to edge, the greatest treachers is saying secrets particully for military and givil leaders, whoever can't keep his nation secrets is an enemy.
\end{abstract}




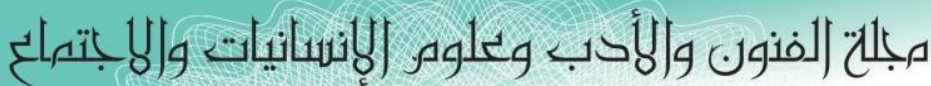

Journal of Arts, Literature, Humanities and Social Sciences

ISSN online: 2414 - 3383

ISSN print: 2616 - 3810

\section{العدد (43) ايلول -سبتمبر 2019}

الحمد الله رب العالمين والصلاة الصداة والسلام على نبينا محمد صلى الله عليه وسلم و على آله و أصحابه ومن تبعهم

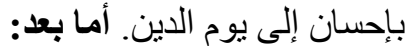
فإنا نريد أن نوضح لوان لكم في حياة النبي صلى الله عليه ولئ وسلم العسكرية، وأمثلة رائعة في ( كتمان الأسرار في

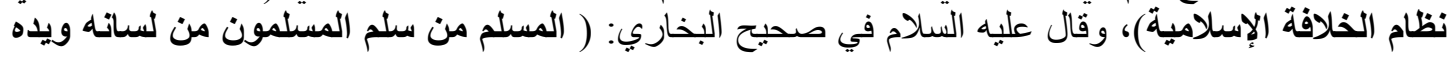

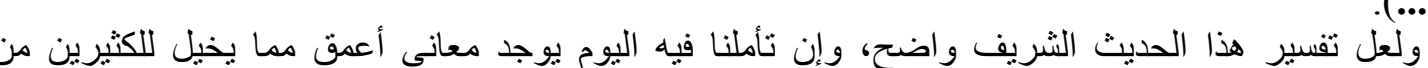

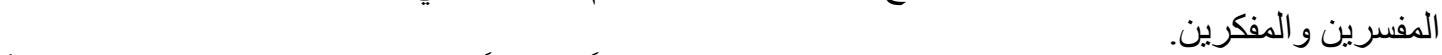
فالمسلم الذي يذيع أسرار إخوانه المسلمين قد يلحق بهم ضرراً مصيراً يودي بهم إلى الدرك الأسفل، وذلاً

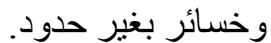
الكتمان و لا يز ال وسيبقى من سجايا الإسلامي الأصيل، وفيل وفوق ذلك فهو عند المسلم دين، لأن الأسر ار فيه قضية الأمة ومصير ها أحياناً، واجب التمسك به في السلم و الحرب.

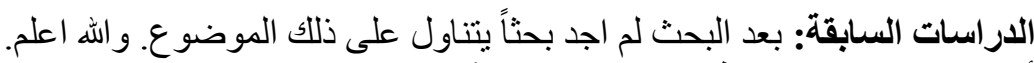

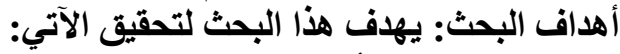

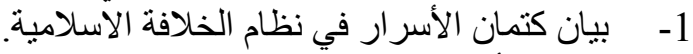

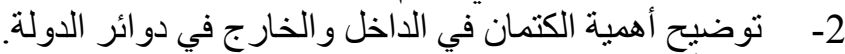

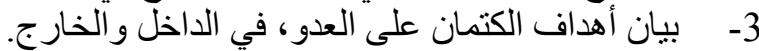

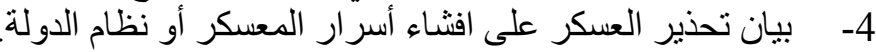
منهج البحث: يسلك الباحث منهج الوصفي و التاريخي و التحليلي.

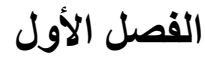 كتمان الأسرار}

كتمان في اللغة: كتمت الثيء، كتما وكتمانا. وسر كاتم، أي مكتوم. ومكتم بالتشديد: بولغ في كتمانه. واستكتمته

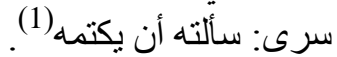

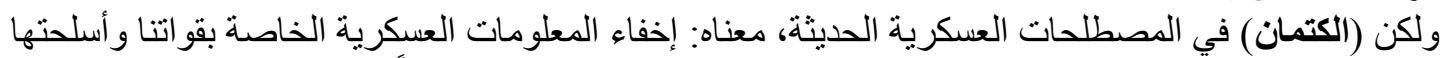

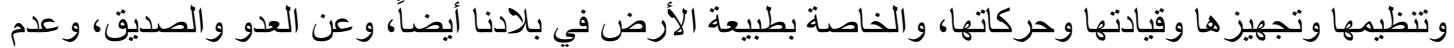
إفتشاء الأسر ار العسكرية مهمة كانت أم غير مهمة، وصغيرة كانت أم كبيرة، وتافهة كانت أم خطبرة، لكان الكل إنسان سواء كان عدواً أم صديقاً. وكتمان المعلومات العسكرية عن العدو لا يحتاج إلى بيان من شدة خطره ونتائجه أيضاً على الدولة الإسلامية

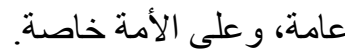
ولكن كتمان الأسرار العسكرية عن الصدية الصديق يحتاج إلى بيان: الصديق نوعان: نوع لله علاقة بالقضايا العسكرية، فإذإِ كان هذا الئان الصديق فوق الثبهات عن المعلومات فلا بأس

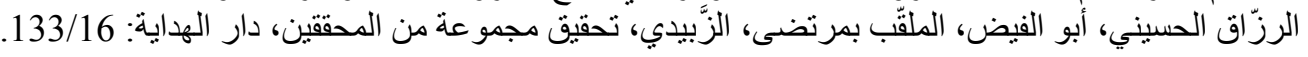


مجلحت (لفنون والأدب وتلوه الإنسانيات والبانتهاع

Journal of Arts, Literature, Humanities and Social Sciences

ISSN online: 2414 - 3383

ISSN print: 2616 - 3810

\section{العدد (43) ايلول -سبتمبر 2019}

من اطلاعه على أسرار المعلومات العسكرية التي لهاصلة مبانشرة بعطله وو اجباته العسكرية.

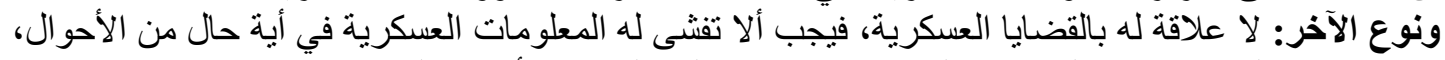

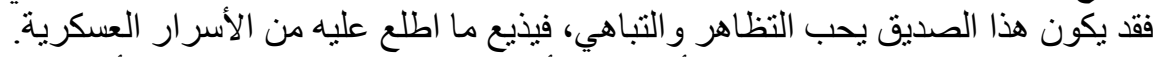

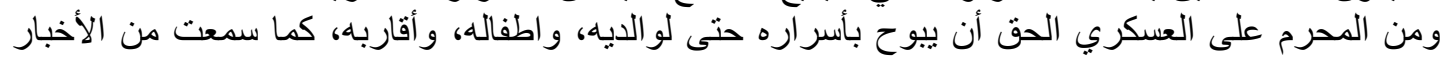

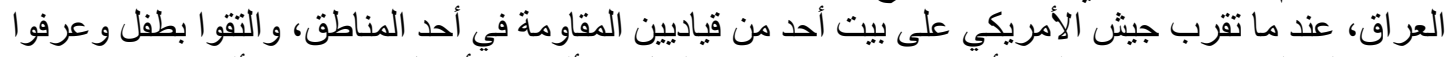

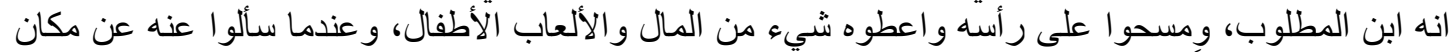

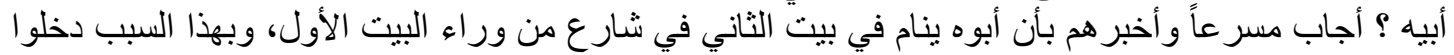
عليه و اعتقلو ا. وفي تاريخ العسكري أمثلة كثيرة، نذكر كيف استطاع العدو أن بطلع على الأسرار العسكرية من عوائل

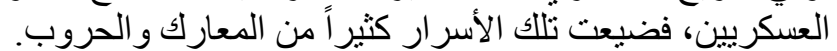

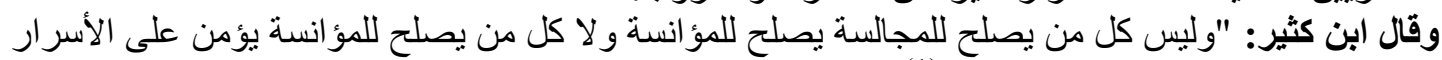

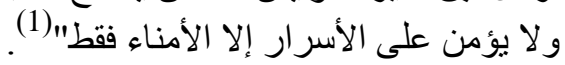
إن كتمان الأسر ار العسكرية يجب أن الأن تبقى في طيّ الكتمان الثديد، و لا عذر لمن يذيعها بحجة أو بأخرى للعدو

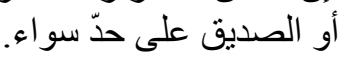

والذي يطلع على الأسرار العسكرية في نظام الخلافة الإسلامية يجب أن يصونها بالكتمان، لا فرق في ذلك بين

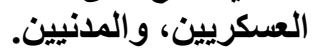

\section{الفصل الثماني \\ أهمية الكتمان النيان}

لقد كان من جملة أسباب انتصار إسرائيل على الإسلام و المسلمين في حرب حزيران (يونو 1967م) هو أن أن إنهان

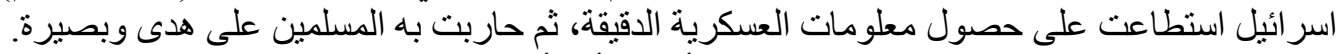

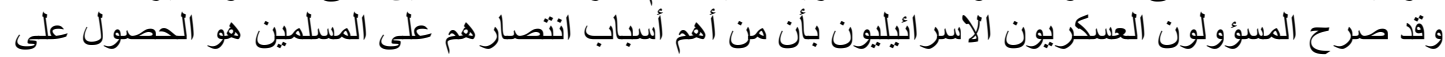

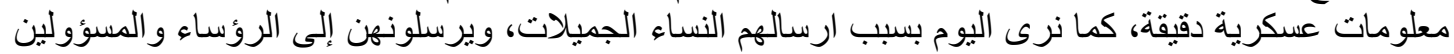

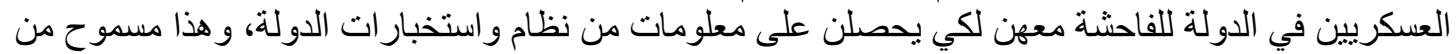

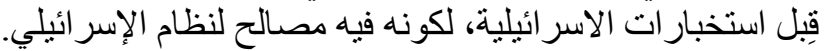

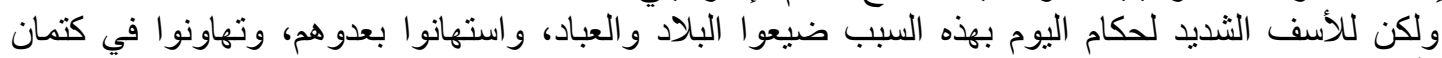

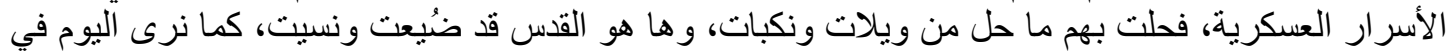

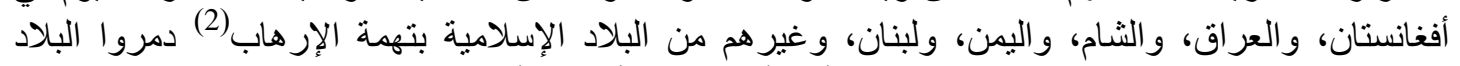

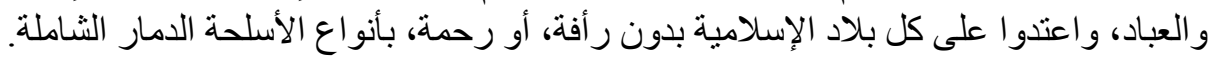

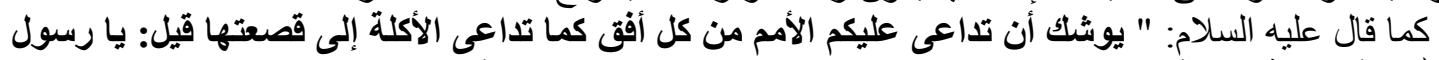

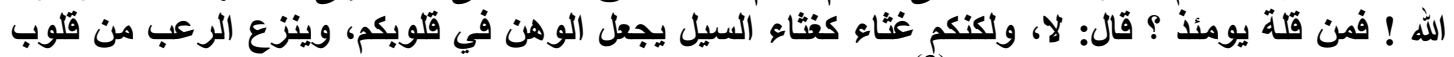

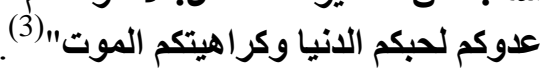

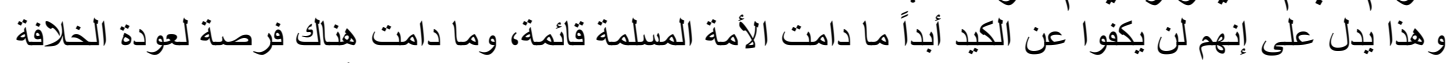

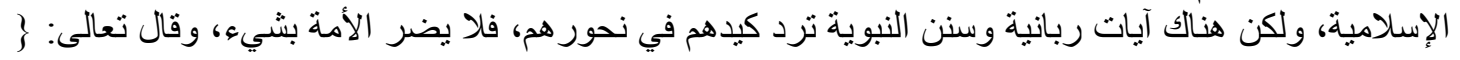

(1) ابن كثير ، البداية والنهاية، لإسماعيل بن عمر بن كثير القرشي أبو الفداء، مكتبة المعارف - بيروت. 296/11.

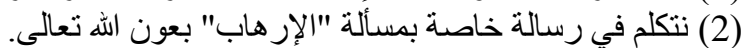
(3) رواه الآمام احمد في مسنده، رقم: 22397: 82/37، وصلى وصححه الألباني في صحيح وضعيف الجامع الصغير، رقم: .143/29:14143 


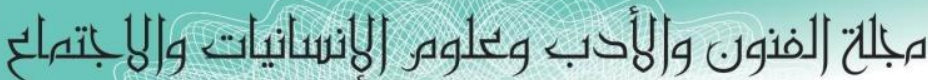

Journal of Arts, Literature, Humanities and Social Sciences

ISSN online: 2414 - 3383

ISSN print: 2616 - 3810

\section{العدد (43) ايلول - سبتهبر 2019}

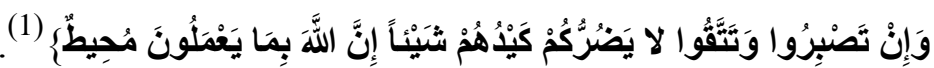

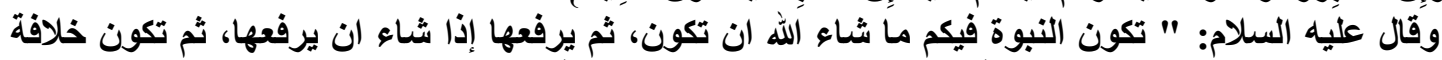

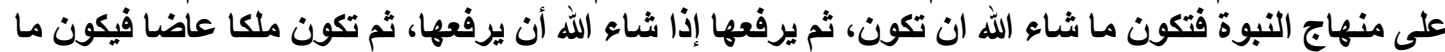

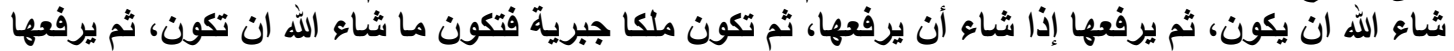

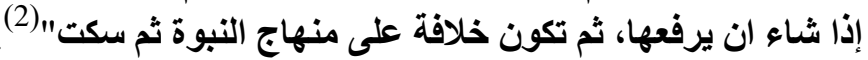

و هذا من اعظم البشرى للأمة، إن بعد الليل فجرًا، وإن مع العسر يسرًا، وإن المستقبل للإسلام، وهو عودة

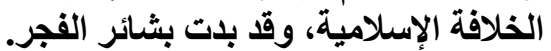

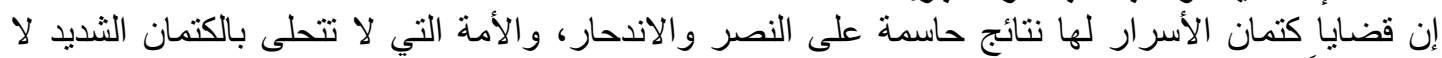
تنتصر أبداً.

\section{الفصل الثالث الثير \\ آثار في كتمان الأسرار}

من المعلوم أن المباغتة(3) مبدأ من أهم مبادئ الحرب، و الكتمان وسيلة من وسائل نطبيق هذا لمبدأ، لأن العدو

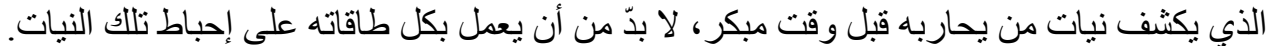

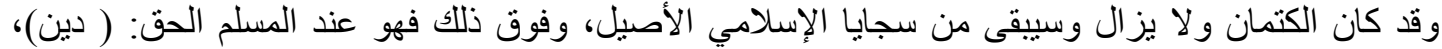

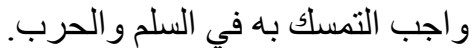
ولو أردنا أن نستقصي ما ولثي ورد في الأدب العربي شعراً ونثراً عن الكتمان، لطال بنا المقال وبعد الثوط، وسأقتصر على بعض الأمثال العربيةً الثائعة:

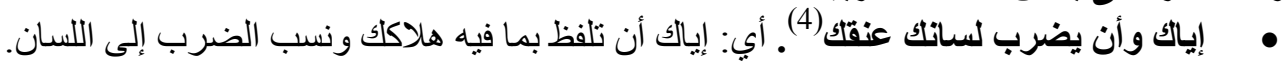

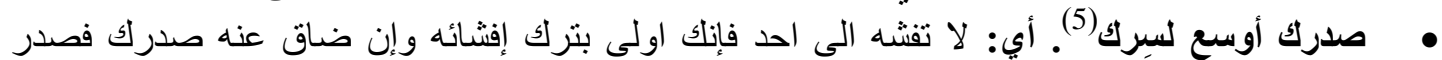
غيرك أضيق عنه، فال الثناعر :

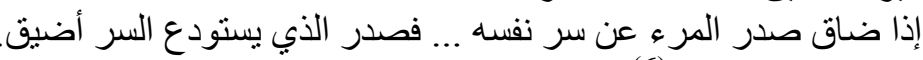

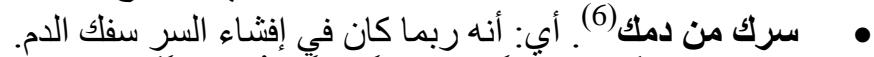

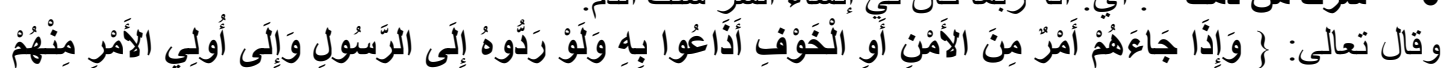

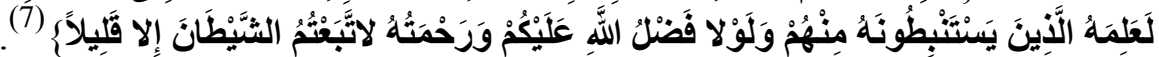

(1) - (1) سورة آل عمران: 120.

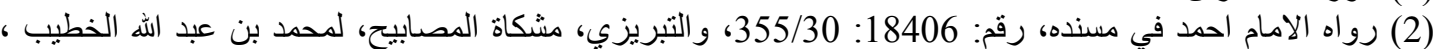

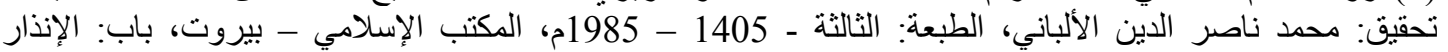

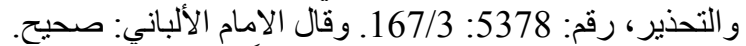

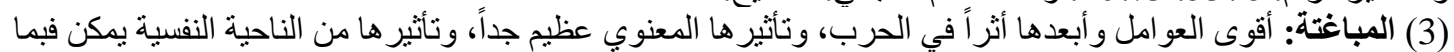

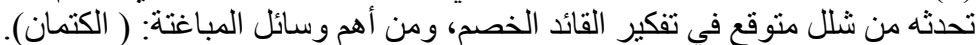
(4) النيسابوري، مجمع الأمثال، لابي الفضل أحمد بن محمد الميداني ، تحقيق: محمد محيى الدين عبد الحميد، دار المعرفة

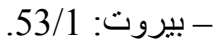
(5) قطامش، جمهرة الأمثال، لأبي هلال العكري، تحقيق: محمد أبو الفضل إبراهيم و عبد المجيد، الطبعة الثانية ،

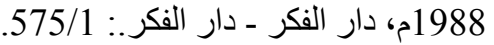
(6) النويري، نهاية الأرب في فنون الفرب الأدب، لشهاب الدين أحمد بن عبد الوهاب، تحقيق: مفيد قدحية وجماعة، الطبعة:

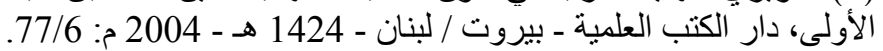

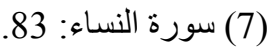




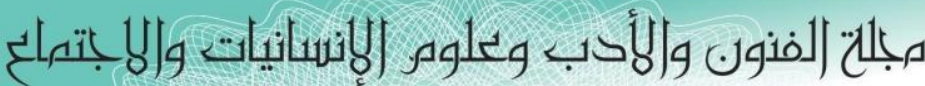

Journal of Arts, Literature, Humanities and Social Sciences

ISSN online: 2414 - 3383

ISSN print: 2616 - 3810

\section{العدد (43) ايلول -سبتمبر 2019}

هذا الأمر اللهي يرشد المسلمين ليس إلى أهية كتمان الأسرار فحسب، بل إلى وجوب إخبار المسؤولين عن كل لإنل

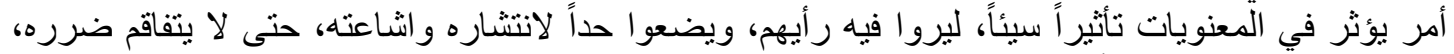

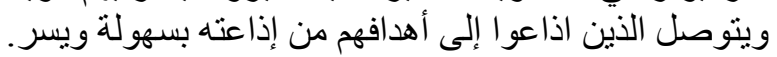

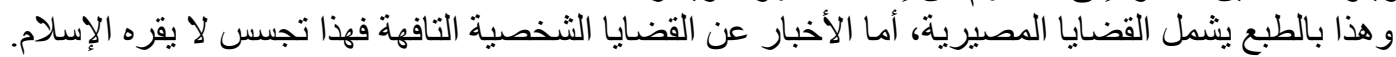

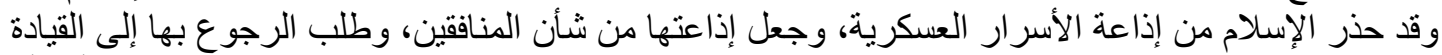

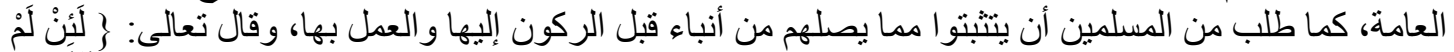

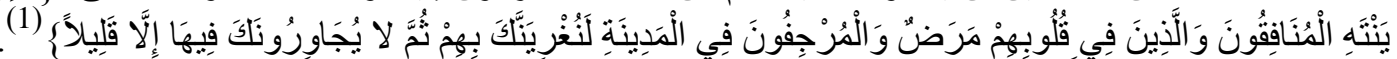

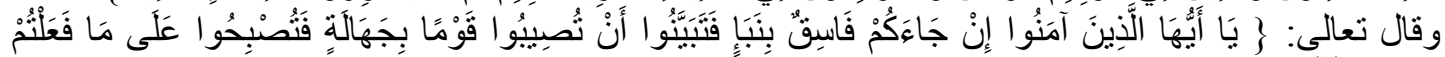
نَادمِِِنَ

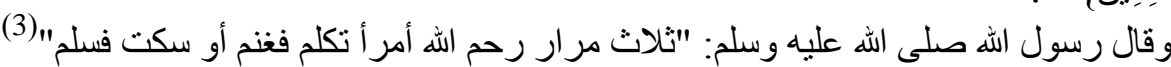

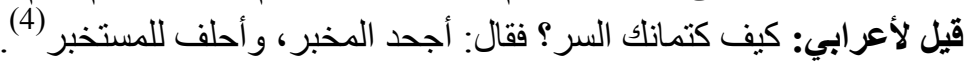

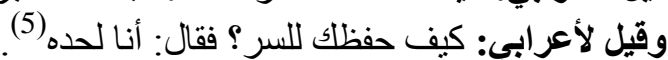

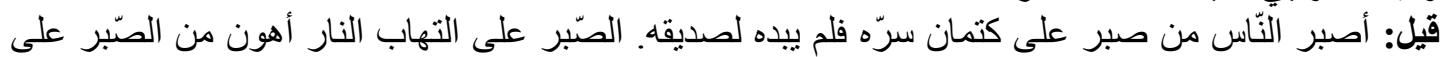
كتمان السرّ.

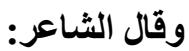

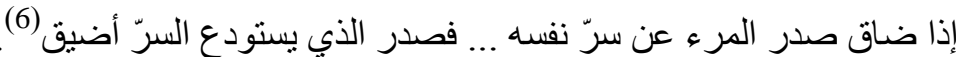

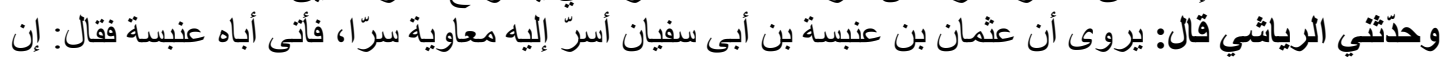

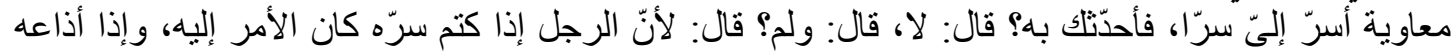

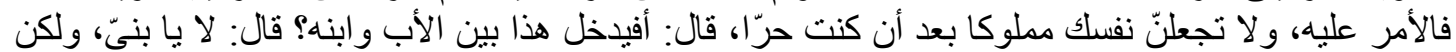

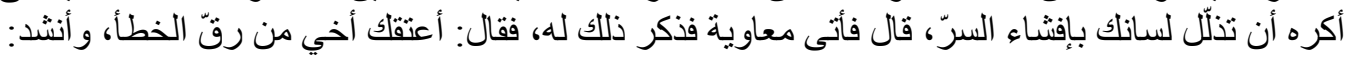

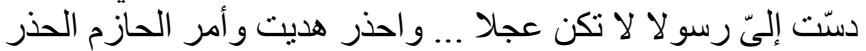

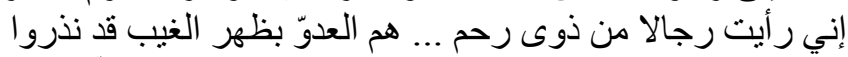

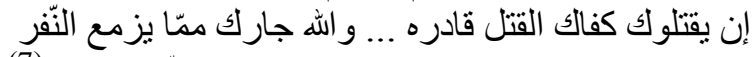

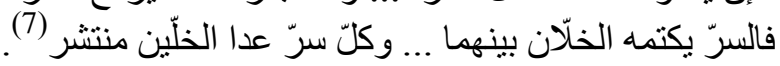

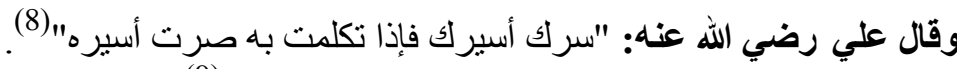
قال بعض الحكماء: "من أفنى سره كثر عليه المتآمرون" (9).

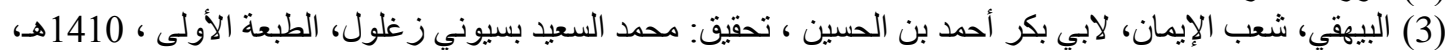

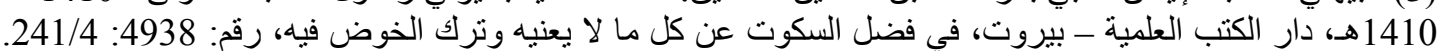
و وقال امام الألباني: حديث حسن.

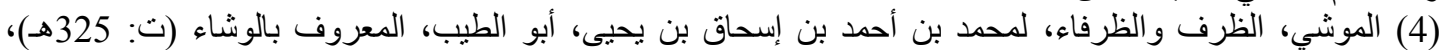

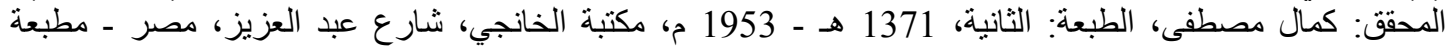

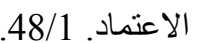

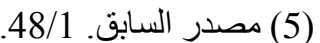

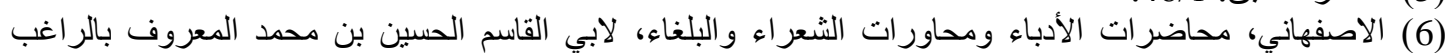

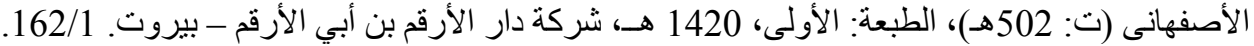

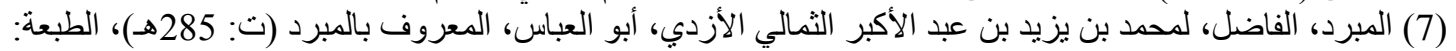

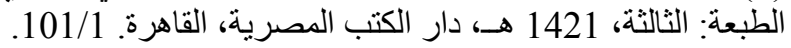

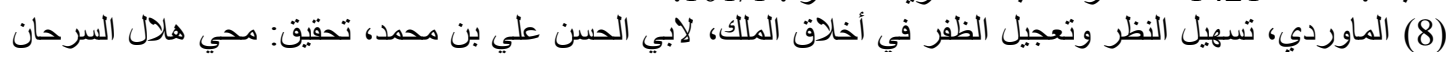

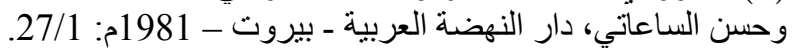
(9) (9) مصدر السابق: 29/1. 


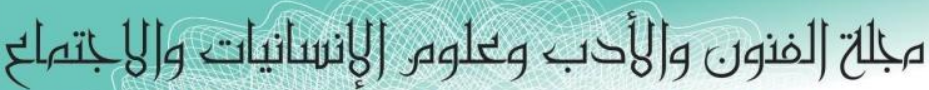

Journal of Arts, Literature, Humanities and Social Sciences

ISSN online: 2414 - 3383

ISSN print: 2616 - 3810

\section{العدد (43) ايلول -سبتمبر 2019}

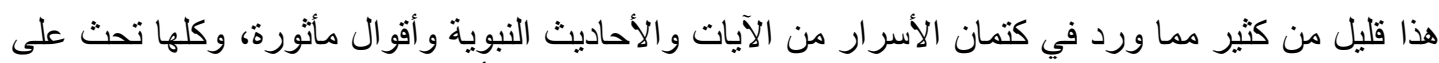

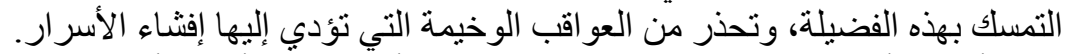

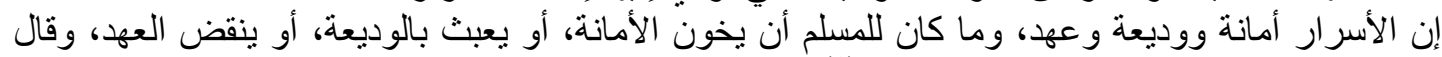

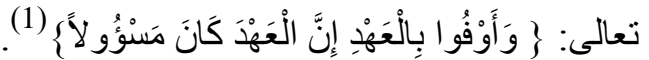

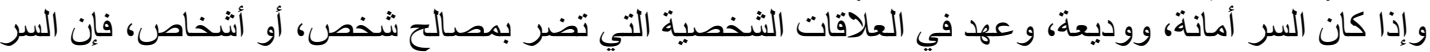

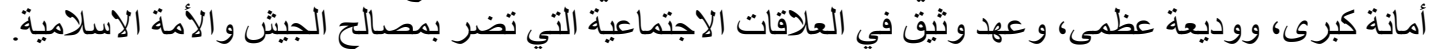

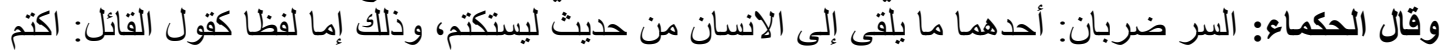

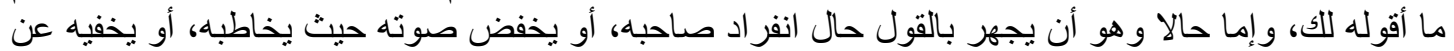

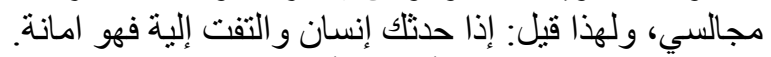

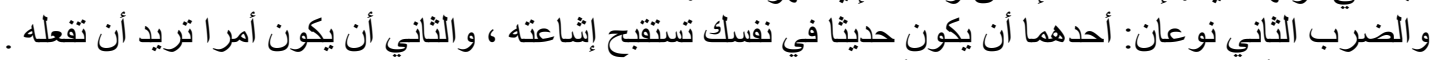

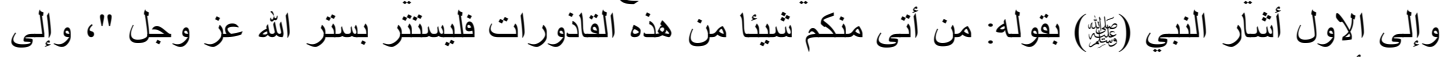

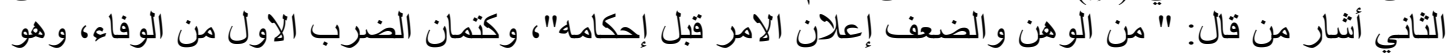

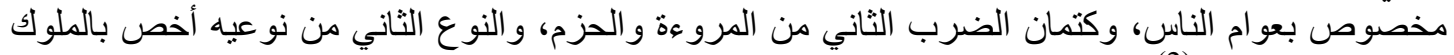

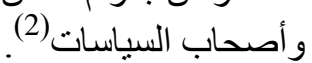
وقيل لأبي مسلم صاحب الدولة: بأبي شيء أدركت هذا الأمر؟ فقال: ارتديت بالكتمان و اتزرت بادئ بالحزم وحالفت

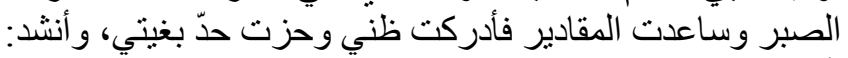

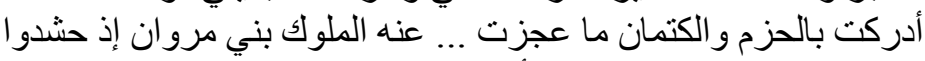

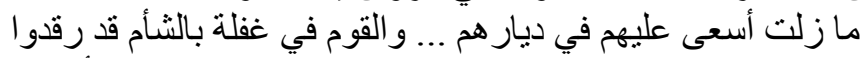

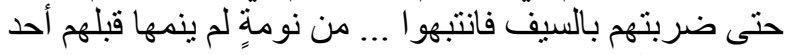

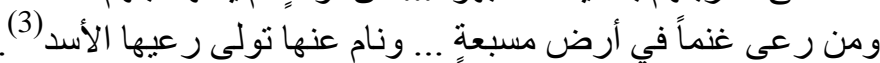
إذاً جاوز الاثثين سر فإنه ... بنتُّ وتكثير الوشاة قمينُ وقال قيس بن الخطيم الأنصاري:

وقد أكثرت الثعر اء في هذا المعنى. وقال رجل من سلف العلماء: كان يقال: أملك الناس لنفسئ من كتم سره من صديقه وخليله.

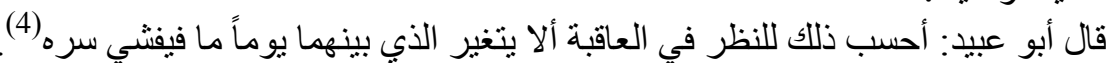

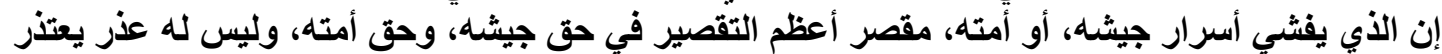
به حتى أمام اللَّ سبحانه وتعالى، وثئه أو أمام الناس.

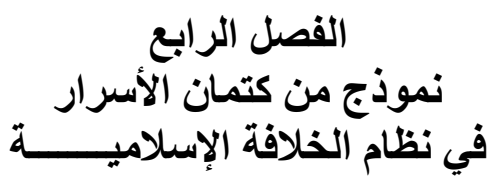

الدروس العملية التي يستطيع المسلمون أن يتعلمو ها من الرسول القائد عليه الصلاة و السلام في كتمان الأسرار

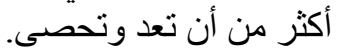
وسأقتصر على نماذج قليلة من الدروس العلمية المستنبطة من غزوات النبي في وسرائه وساه، حتى يعرف 


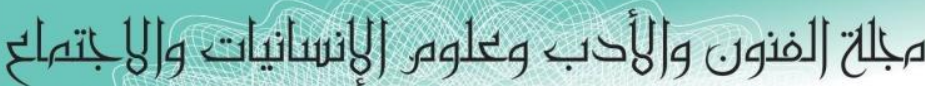

Journal of Arts, Literature, Humanities and Social Sciences

ISSN online: 2414 - 3383

ISSN print: 2616 - 3810

\section{العدد (43) ايلول - سبتمبر 2019}

العسكريون المسلمون و المدنيون أيضاً كيف كان عليه الصلاة والسلام يعتمد أقصى درجات الكيكات الكتمان في بناء

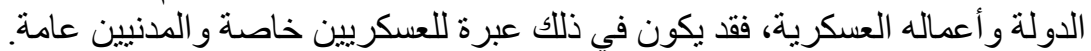

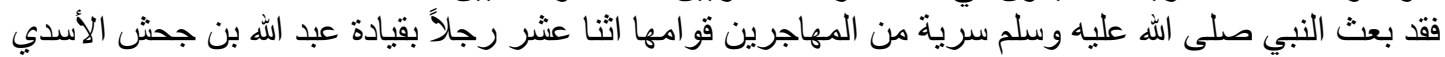

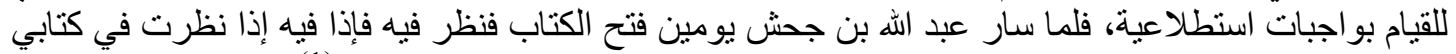

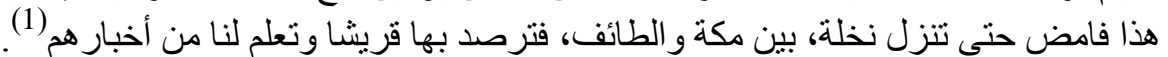

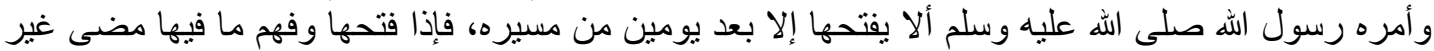
مستكره وحتى من أفر اده الذين معله الذه

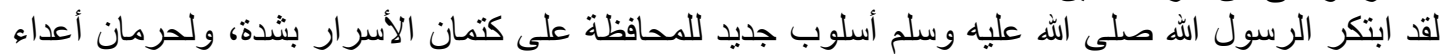

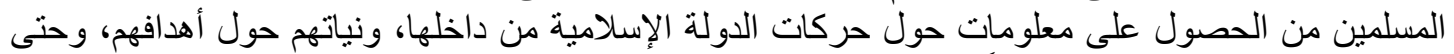
أخفى نياته عن العدو والصديق كائناً من كان.

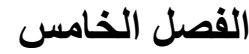 \\ مباغتة حربية

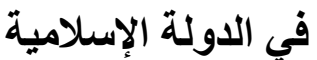

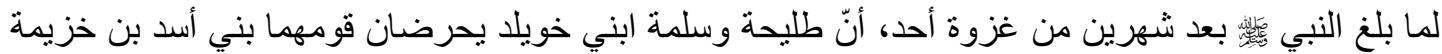

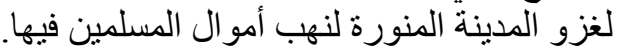

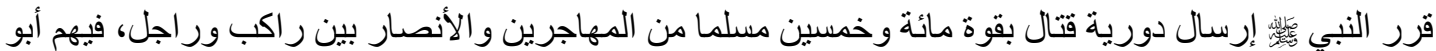

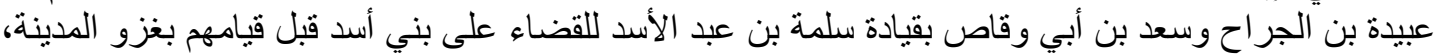

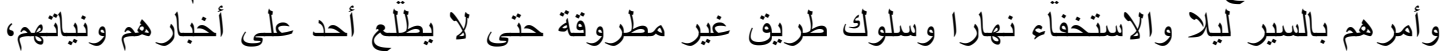

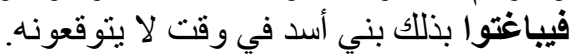
وسار أبو سلمة حتى وصنل الى ديار بني أسد دون أن أن يعرفوا عن حركته إليهم شيئا فأحاط بهم فجر ا فلم يسنطع

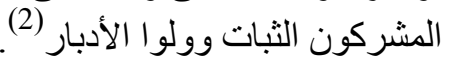

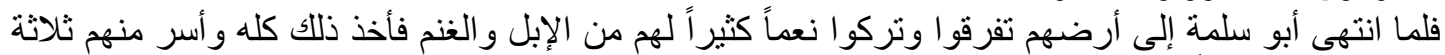
مماليك و أقبل راجعاً بهم إلى المدينة. والارس الكبير القَيم الذي يمكن استنباطه هو كتمان الذان الأسرار عن جيشنا من قبل العدو على أهدافها والامتناع عن نشر أخبار ها أمام عوام الناس، أو الإعلام.

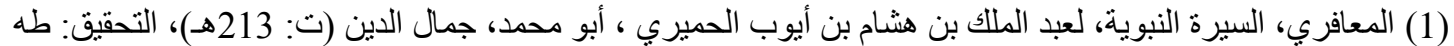

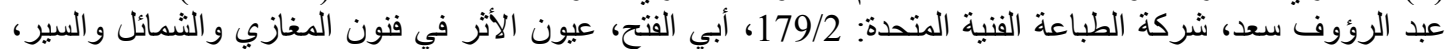

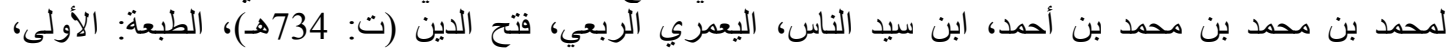

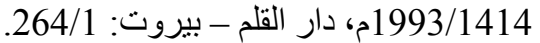

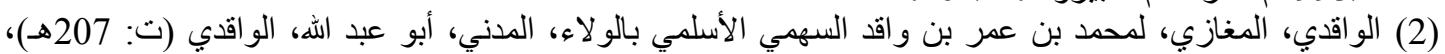

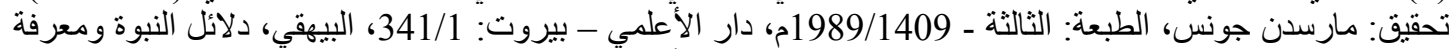

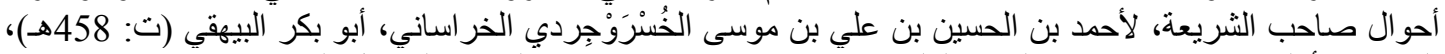

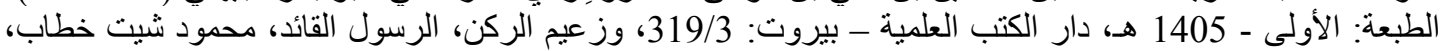
طبعة الثانية، مكتبة النهضةــ بغداد 1960م: 203/1. 


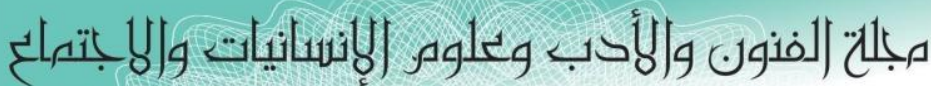

Journal of Arts, Literature, Humanities and Social Sciences

ISSN online: 2414 - 3383

ISSN print: 2616 - 3810

\section{العدد (43) ايلول - سبتهبر 2019}

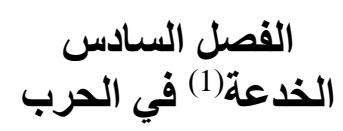

و لا وثوق في الحرب بالظّفر، و وإن حصلت أسبابه من العدّة والعديد، و إنّما الظّفر فيها و الغلب من قبيل البحث

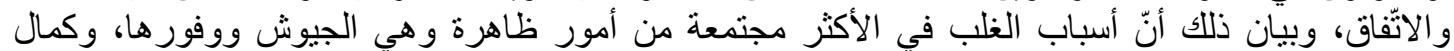

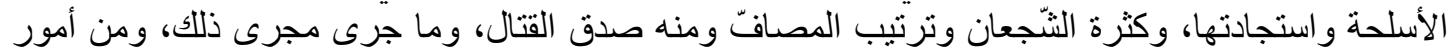

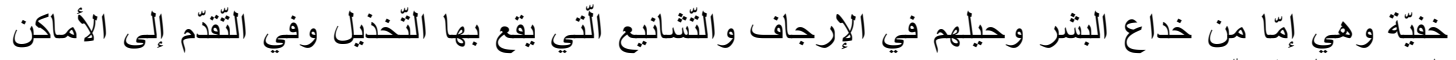
الكمون و المطمئنّ. و إمّا أن تكون تللك الأسباب الخفيّة أمور اسماويّة، لا قدرة للبشر على اكتسابها تلقى في القلوب فيستولي الرّهب

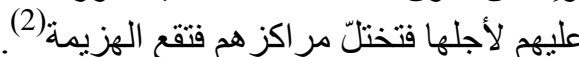

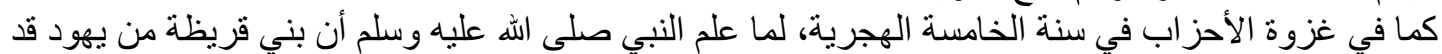

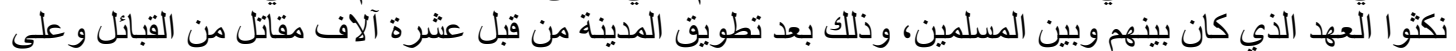
رأسهم قريش، وبني سُّليم، وبني أسد.

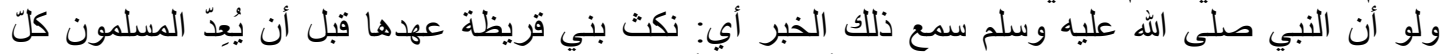

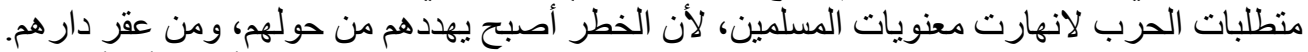

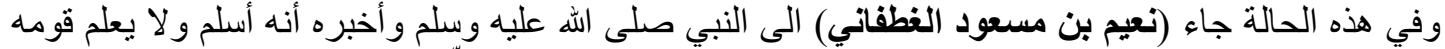

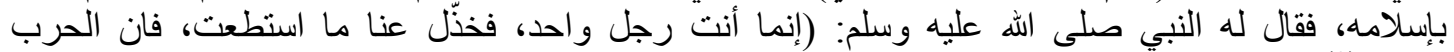

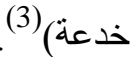

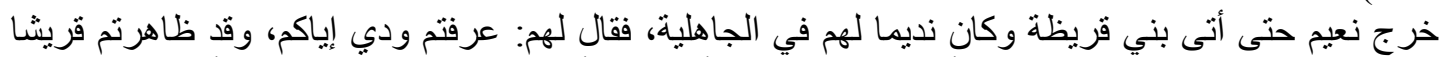

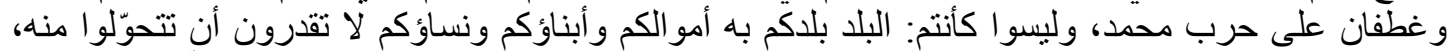

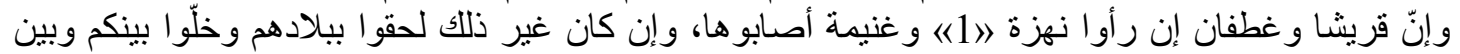

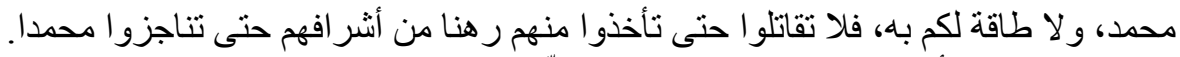

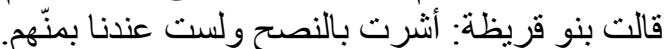

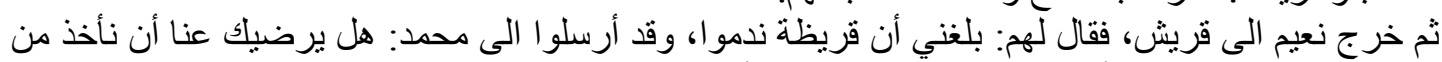

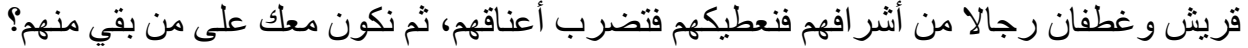

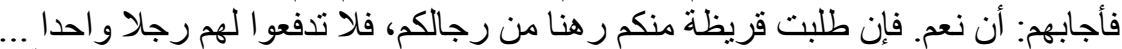

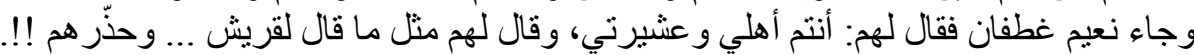

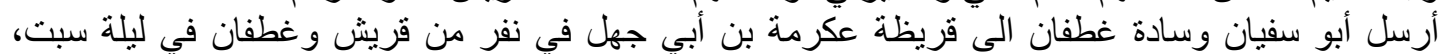

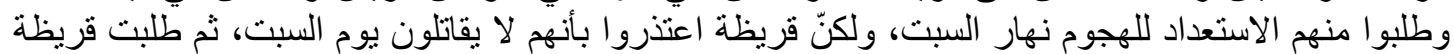

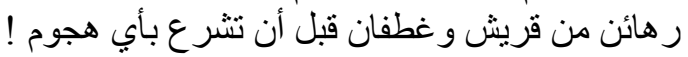

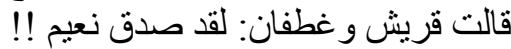
ولما رفض طلب قريظة بإعطائها رهائن من قريش و وغطفان قالت: لقد صدق نعيم (4)!

(1) الذدعة: أي: إذا تخلق بغير خلقه، لأنه يخفي خلاف ما يظهره، ومن أمثال العرب اربّ حيلة أنفع من قبيلة|). ينظر:

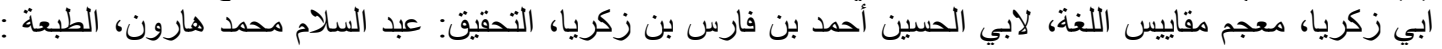

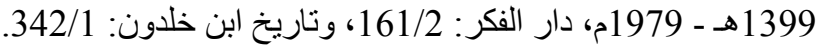

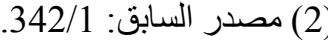

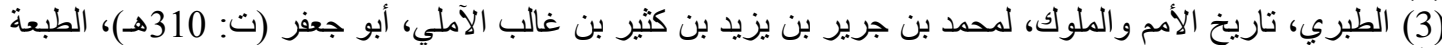

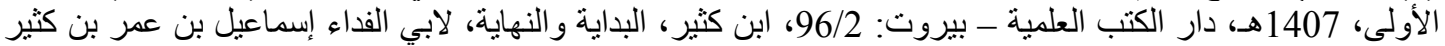

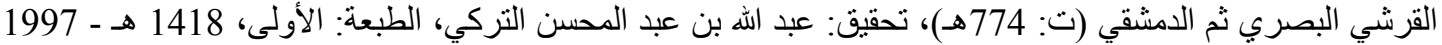

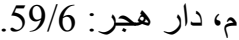
(4) مسكويه، تجارب الأمم وتعاقب الهمم، لابي علي أحمد بن محمد بن يعقوب (ت: 421هـ)، التحقيق: أبو القاسم إمامي، الطبعة: الثانية، 2000 م، سروش- طهر ان.: 259/1. 


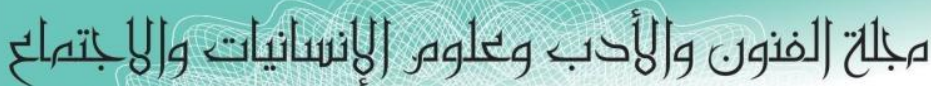

Journal of Arts, Literature, Humanities and Social Sciences

ISSN online: 2414 - 3383

ISSN print: 2616 - 3810

\section{العدد (43) ايلول -سبتمبر 2019}

وفي هذه الحالة من التفرق والاختلاف بين الأحز اب أرسل النبي صلى الله عليه وسلم ابو حذيفة اليماني كعين

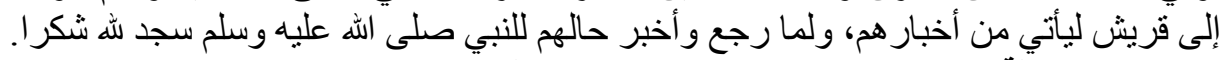
والحرب الحديثة تعتمد على تلك البث والاشئاعات المثيرة بين الدول، وصفوف الجيش المقابل، وبلبلة الأفكار في تلكا البلا المحارب. فإن النبي صلى الله عليه وسلم له مو اقف كثيرة وطريفة في هذه الحالات في الحرب، و إن أردنا أن ونثير إليه

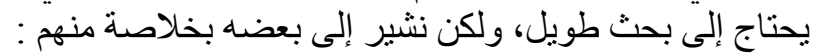

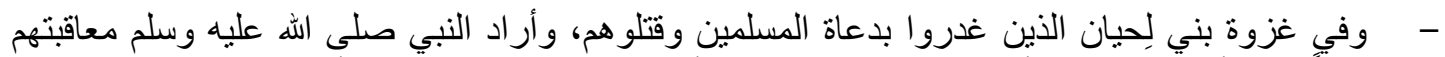

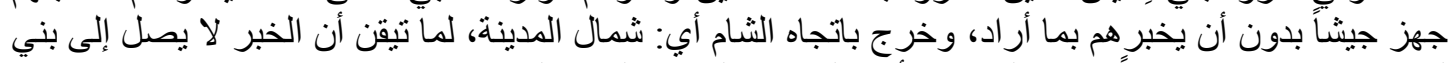

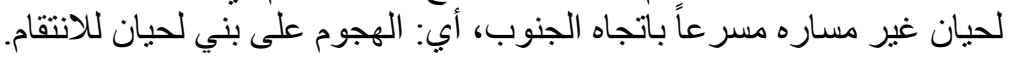

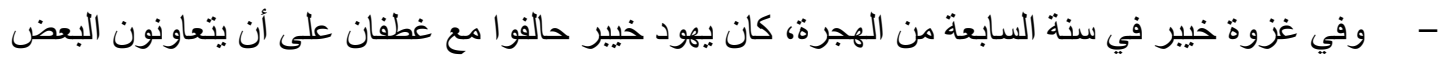

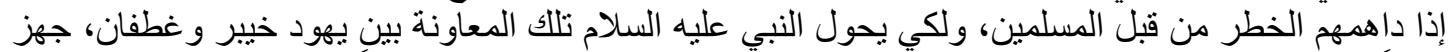

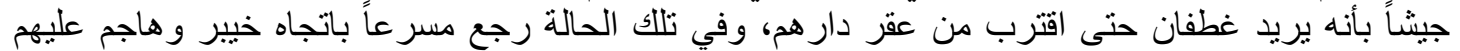

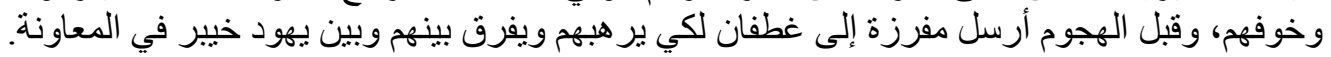

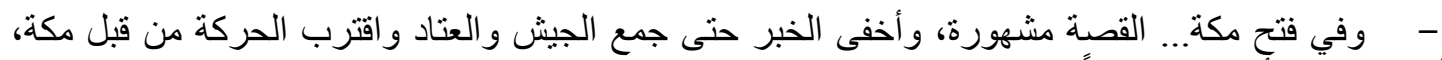

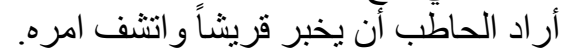
وأهم شيء في انتصار المسلمين في الحرب هو الكتمان الأسرار، لذلك نجحوا في تلك الحروب، والفتوحات على الأمم.

الخاتمة

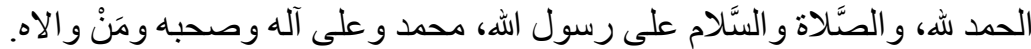

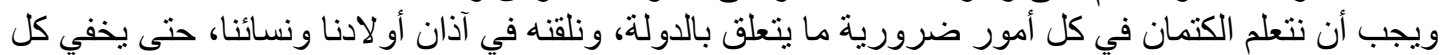

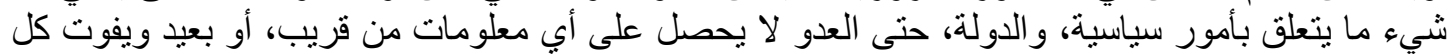

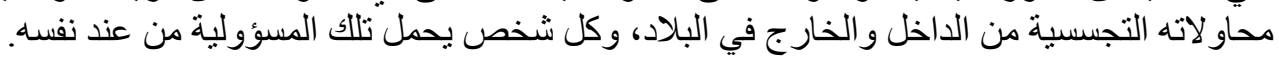

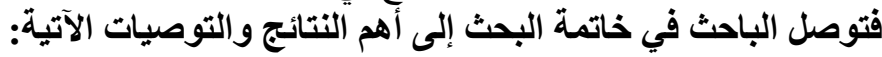

أولاً: أهمٌُ النتائج ما توصل إليه الباحث:

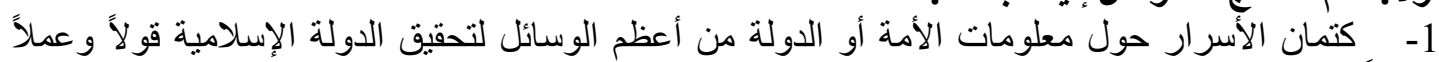
وو اقعاً. 2 - التمسك بالوحيين الثريفين هو الضابط الأساسي لهذا الهدف المرجو. 3- أهمية دور الأمر بالمعروف و النهي عن المنكر وأهمية دور الجهاد ومدافعة أعداء الأمة في تحقيق الدولة

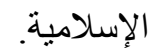
4- ومن اعظم البشرى للأمة، إن بعد الليل فجرًا، و إن مع العسر يسرًا، و إن المستقبل للإسلام، وهو عودة

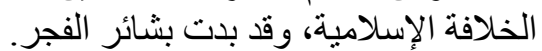

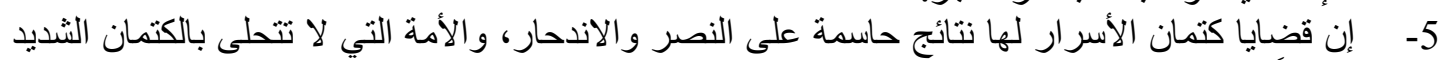
لا تلتصر أبداً.

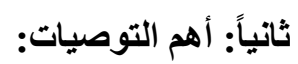

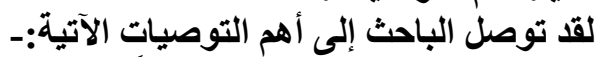

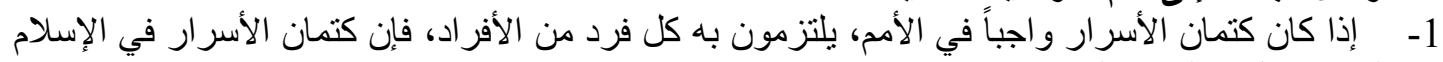
دين يلتزم به كل مسلم ومسلمة صحيح الإيمان.

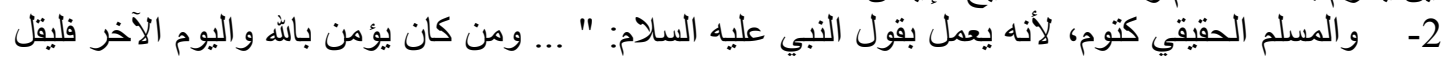




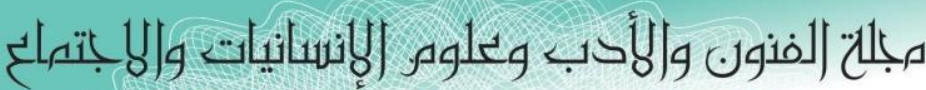

Journal of Arts, Literature, Humanities and Social Sciences

ISSN online: 2414 - 3383

ISSN print: 2616 - 3810

\section{العدد (43) ايلول - سبتهبر 2019}

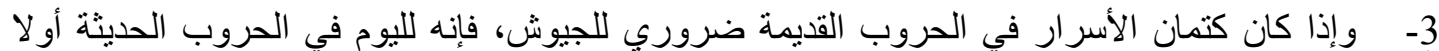

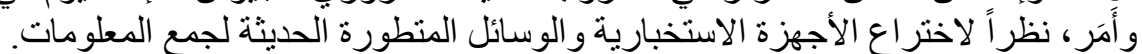

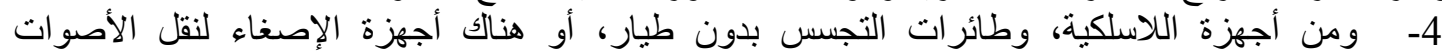
و الهمسات داخل المباني و الجدران، كما قبل: ( إن للجدران آذاني).

والحمد لله على نعمة الإسلام، والسلام على من اتبع واهتدى، وصلى الله على محمد وعلى آله وصحبه وسلم

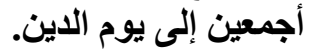

1- ابن حنبل، مسند الإمام أحمد بن حنبل، لأحمد بن حنبل، التحقيق: شعيب الأرنؤوط و آخرون، الطبعة: الثانية

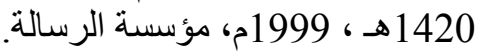

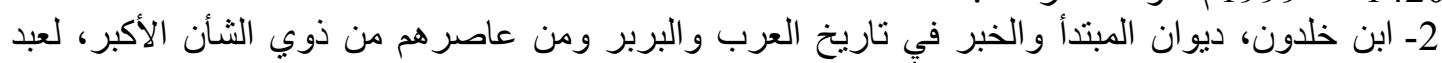

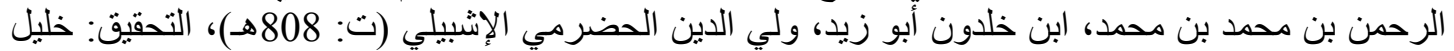

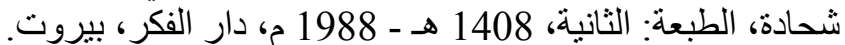

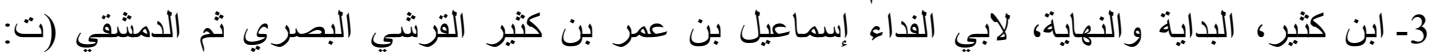

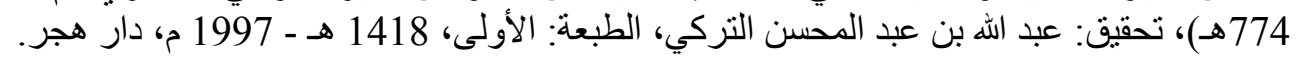

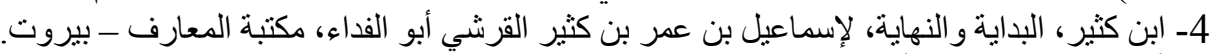

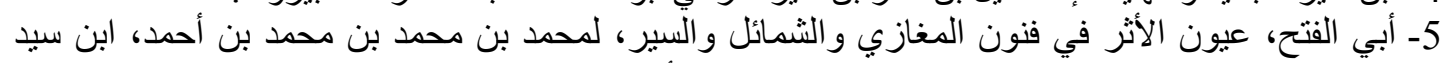

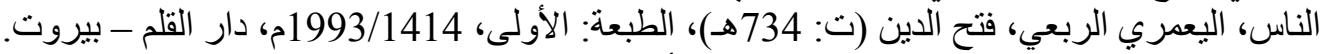

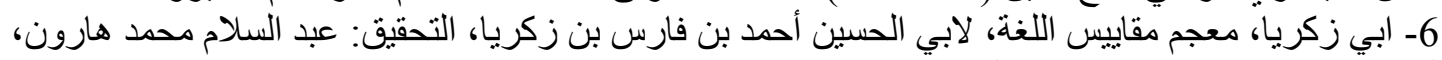

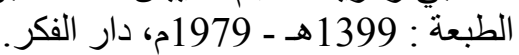

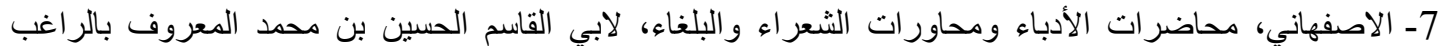

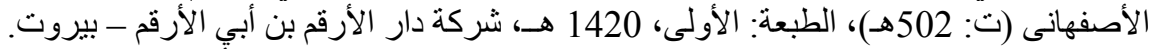

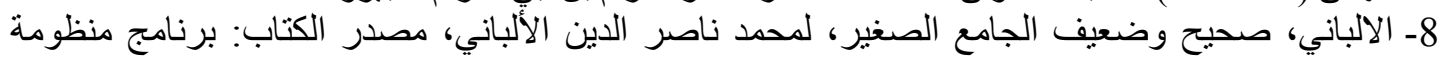

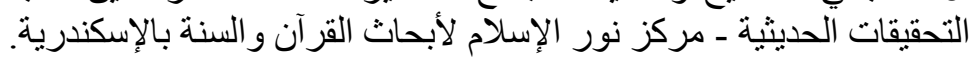

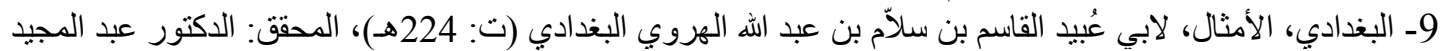

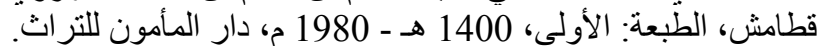

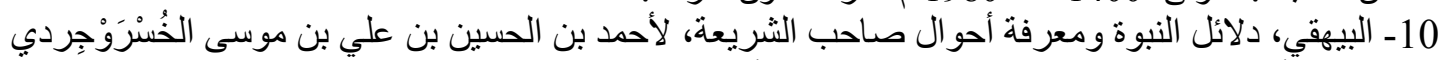

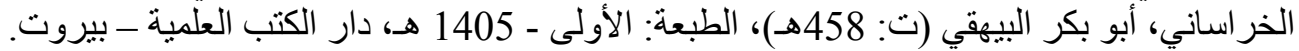

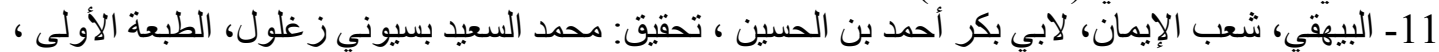

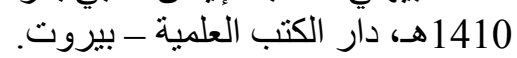

12- التبريزي، مشكاة الهصابيح، لمحمد بن عبد الله الخطيب ، تحقيق: محمد ناصر الدين الألباني، الطبعة:

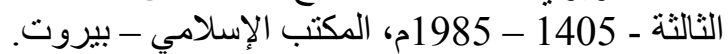

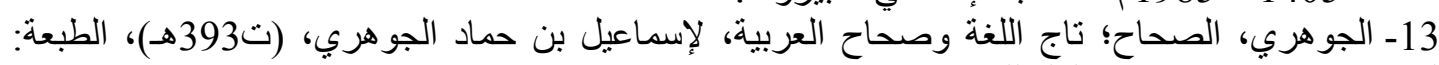

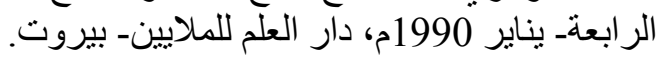

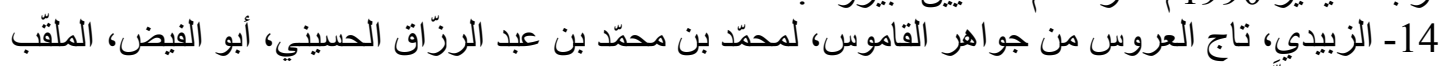

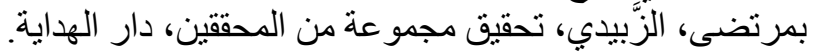

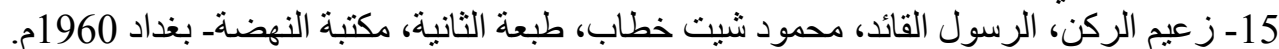

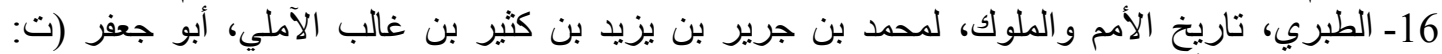

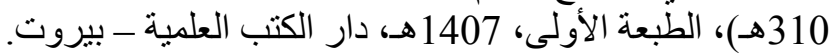




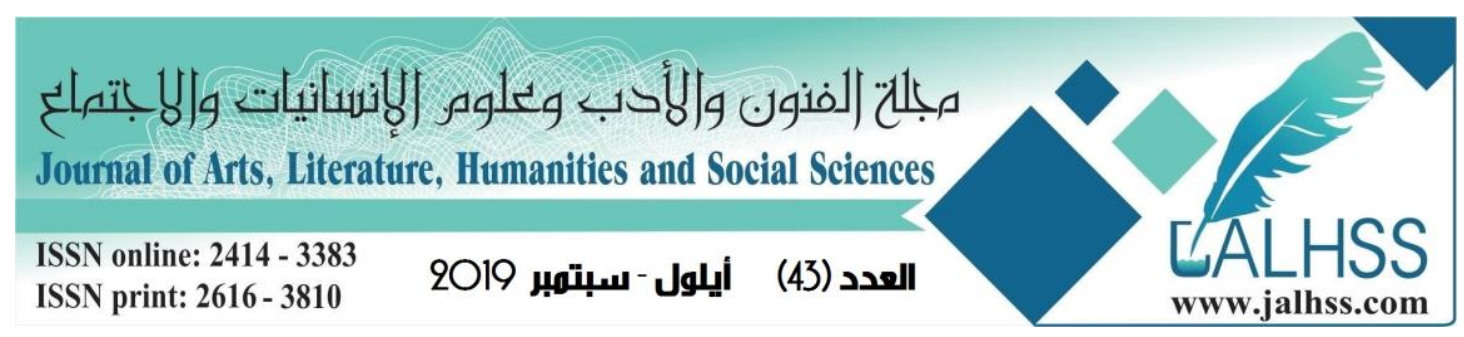

17- قطامش، جمهرة الأمثال، لأبي هلال العسكري، تحقيق: محمد أبو الفضل إبراهيم وعبد المجيد، الطبعة

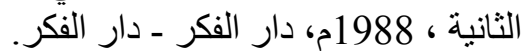

18ـ الماوردي، تسهيل النظر وتعجيل الظفر في أخلاق الملك، لابي الحسن علي بن محمد، تحقيق: محي هلال

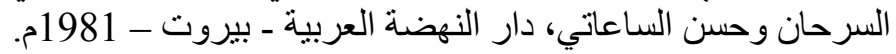

19- المبرد، الفاضل، لمحمد بن بزيد بن عبد الأكبر الثمالي الأزدي، أبو العباس، المعروف بالمبردة المبرد (ت: 285هـ)،

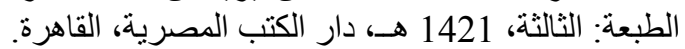

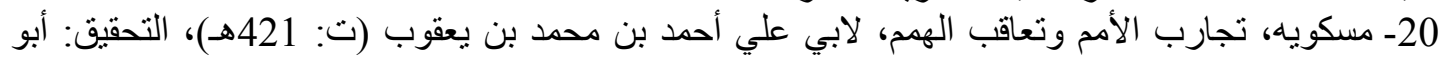

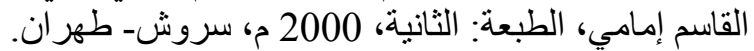

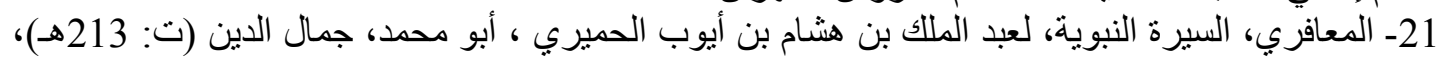
التحقيق: طه عبد الرؤوف سعد، شركة الطباعة الفنية المتحدة.

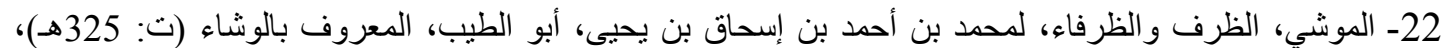

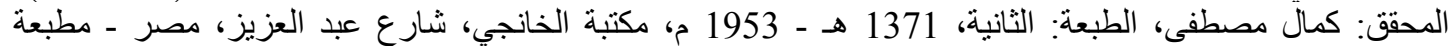

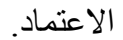

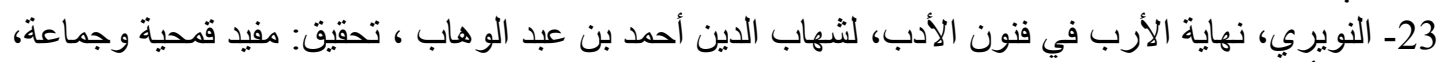

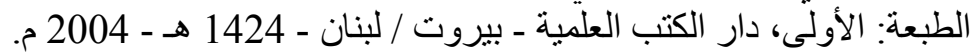

24- النيسابوري، مجمع الأمثال، لابي الفضل أحمد بن محمد الميداني ، تحقيق: محمد محيى الدين عبد الحميد،

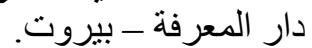

25- الو اقدي، المغازي، لمحمد بن عمر بن و اقد السهمي الأسلمي بالولاء، المدني، أبو عبد الله، الواقدي (ت:

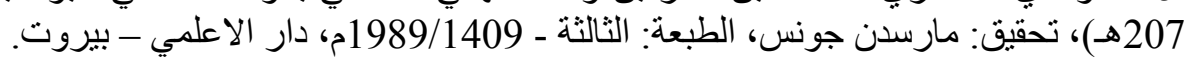

\section{References}

1 - Ibn Hanbal, Musnad Imam Ahmad bin Hanbal, to Ahmed bin Hanbal, investigation: Shoaib Arnaout and others, edition: second 1420 e, 1999, the institution of the message.

2 - Ibn Khaldun, the Court of Debutant and news in the history of the Arabs and Berbers and their contemporary of the most important, for Abdul Rahman bin Mohammed bin Mohammed, Ibn Khaldoun Abu Zaid, Crown of religion Hadrami Seville (Tel: 808 e), Investigation: Khalil Shehadeh, Edition: second, 1408H - 1988 AD, Dar Al Fikr, Beirut.

3 - Ibn Katheer, the beginning and the end, the father of redemption Ismail bin Omar bin Katheer Al-Qurashi Al-Basri and then Damascene (T: $774 \mathrm{AH})$, realization: Abdullah bin Abdul Mohsen Al-Turki, Edition: First, 1418 e - 1997 AD, Dar Hajar.

4 - Ibn Katheer, the beginning and the end, by Ismail bin Omar bin Katheer AlQurashi Abu al-Fida, Library of Knowledge - Beirut.

5 - Abu al-Fath, eyes of the impact in the arts of the magazines and merits and biographies, by Mohammed bin Mohammed bin Mohammed bin Ahmed, the son of people, Alaamri quarter, Fath al-Din (Tel: 734 e), Edition: First, 1414/1993, Dar AlQalam - Beirut.

6 - Abi Zakaria, Dictionary of Language Standards, Abi Hussein Ahmed bin Faris bin Zakaria, Investigation: Abdul Salam Mohammed Haroun, Edition: 1399 AH 1979 AD, Dar thought. 


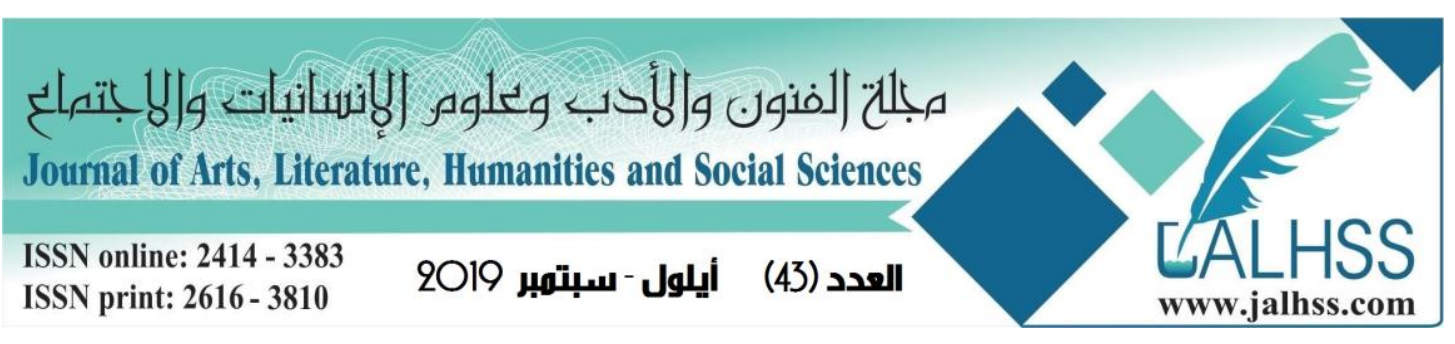

7 - Isfahani, lectures writers and interviews of poets and rhetoric, to Abu al-Qasim Hussein bin Mohammed known Ragheb Isfahani (Tel: 502 e), edition: the first, 1420 e, Dar Al Arqam bin Abi Al Arqam - Beirut.

8 - Albanian, true and weak small mosque, by Mohammed Nasser al-Din al-Albani, the source of the book: Modern Investigation System Program - Noor Islam Center for Quran and Sunnah Research in Alexandria.

9 - Baghdadi, proverbs, Abu Obaid al-Qasim bin Salam bin Abdullah Herawi Baghdadi (Tel: 224 e), the investigator: Dr. Abdul Majid Katamish, Edition: the first, $1400 \mathrm{AH}-1980$, the safe house of heritage.

10 - Al-Bayhaqi, the signs of prophecy and knowledge of the conditions of the owner of the law, to Ahmed bin Hussein bin Ali bin Musa al-Khosrojerdi al-Khorasani, Abu Bakr al-Bayhaqi (Tel: 458 e), edition: the first - 1405 e, Scientific Books House Beirut.

11- Al-Bayhaqi, People of Faith, by Abi Bakr Ahmed Bin Al-Hussein, Achieved by: Mohamed El-Said Bassiouni Zaghloul, First Edition, 1410 AH, Scientific Books House - Beirut.

12- Tabrizi, Mishkat al-Misbah, by Mohammed bin Abdullah al-Khatib, Achieved by: Muhammad Nasser al-Din al-Albaani, 3rd edition, 1405-1985, Islamic Bureau, Beirut.

13- Al-Jawhary, Al-Sahah; The Crown of the Arabic Language and Al-Sahah, for Isma'il ibn Hammad Al-Jawhary, (d. 393 AH), Fourth Edition, January 1990, Dar AlIlm for the Millions, Beirut.

14 - Zubaidi, crown bride of the jewels dictionary, to Mohammed bin Mohammed bin Abdul Razzaq Husseini, Abu Fayd, nicknamed Murtaza, Zubaidi, the investigation of a group of investigators, House guidance.

15 - the leader of the corner, the messenger leader, Mahmoud Shit Khattab, second edition, Library Renaissance - Baghdad 1960.

16 - Tabari, the history of the nations and kings, by Mohammed bin Jarir bin Yazid bin Kathir bin Ghaleb Al-Amali, Abu Jaafar (Tel: 310 e), the first edition, 1407 e, House of scientific books - Beirut.

17- Qatamesh, a group of proverbs, to Abu Hilal military, investigation: Mohammed Abu Fadl Ibrahim and Abdul Majid, second edition, 1988, Dar Al Fikr - Dar Al Fikr.

18 - Mawardi, facilitating the consideration and acceleration of the nail in the morals of the king, to Abi Hassan Ali bin Mohammed, the investigation: Mohi Hilal Sarhan and Hassan watchmaker, Dar Al-Nahda Arab - Beirut - 1981

19 - cooler, the virtuous, Mohammed bin Yazid bin Abdul Akbar Thumali Azadi, Abu Abbas, known as the file (Tel: 285 e), Edition: Third, 1421 e, the Egyptian House of Books, Cairo.

20 - Mesquia, the experiences of the nations and the succession of determination, to Abi Ali Ahmed bin Mohammed bin Jacob (Tel: 421 e), Investigation: Abu Qasim Imami, Edition: Second, 2000, Soroush - Tehran. 


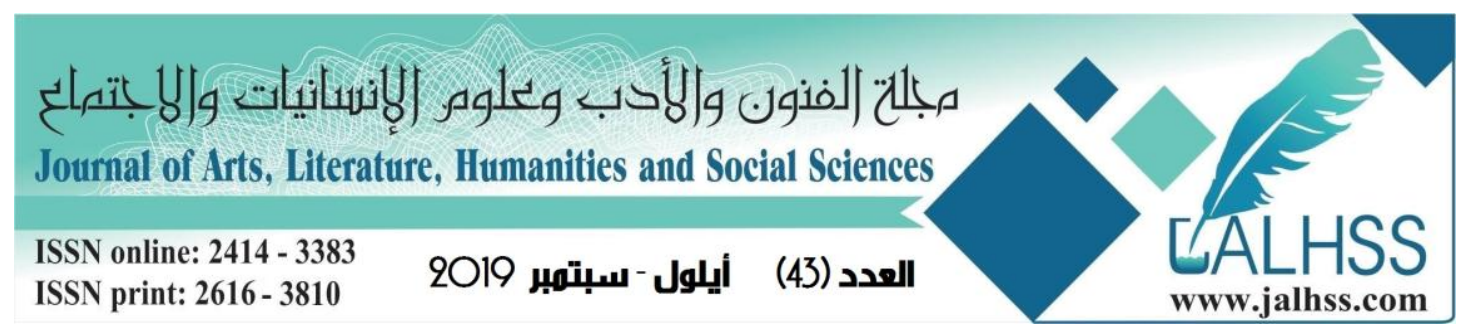

21 - Maafri, biography of the Prophet, to Abdul Malik bin Hisham bin Ayub alHumairi, Abu Mohammed, Jamal al-Din (Tel: 213 e), the investigation: Taha Abdel Raouf Saad, United Technical Printing Company.

22- Moshi, the envelope and the witty, by Mohammed bin Ahmed bin Ishaq bin Yahya, Abu Tayeb, known as Al-Wesha (T: 325 AH), Investigator: Kamal Mustafa, second edition, 1371 AH - 1953 AD, Al-Khanji Library, Abdel Aziz Street, Egypt Accreditation Press.

23 - Nuwairi, the end of the gods in the arts of literature, by Shihab al-Din Ahmed bin Abdul Wahab, investigation: Mufid Qamhieh and group, edition: the first, the scientific books House - Beirut / Lebanon - 1424 e - 2004.

24- Al-Nisaburi, Al-Amthal Complex, by Abi Al-Fadl Ahmed Bin Mohammed AlMaidani, Investigated by: Mohamed Mohieddin Abdel Hamid, Dar Al-Marefa, Beirut.

25- Al-Waqidi, Al-Maghazi, Mohammed bin Omar bin Waqed Al-Sahmi Al-Islami, Al-Madani, Abu Abdullah, Al-Waqadi (Tel: 207), Investigation: Marsden Jones, Third Edition, 1409/1989, Dar Al-Alami, Beirut. 